\title{
Ultimate Aims and Prospects of Inventions
}

\author{
Chien-Hung Liu ${ }^{1, *}$ and Shoou-Jinn Chang ${ }^{2}$
}

Received: 22 September 2015 / Accepted: 22 September 2015 / Published: 29 September 2015

1 Department of Mechanical Engineering, National Chung Hsing University, 250 Kuo Kuang Rd., Taichung 402, Taiwan

2 Institute of Microelectronics \& Department of Electrical Engineering, Center for Micro/Nano Science and Technology, Advanced Optoelectronic Technology Center, National Cheng Kung University, No.1, University Road, Tainan City 701, Taiwan; changsj@mail.ncku.edu.tw

* Correspondence: carus@dragon.nchu.edu.tw; Tel.: +886-4-2284-0433 (ext. 411); Fax: +886-4-2287-7170

Scholars from academic units and research personnel from company research departments are welcome to contribute research papers which are innovative and inventive to the journal Inventions, the founding of which has been embodied with three very important aims:

The first is the timely publication, spread and promotion of innovative and inventive research papers.

The second is to guide research scholars in extending basic theoretic research to innovative and inventive research results.

The third is the prospect of this journal, which is to help authors present their research results to industry for the promotion of technology transfer.

The realization of the second and third aims makes Inventions different from other journals, and further shows the value of its foundation and existence. Many scholars spend their lives publishing research papers in many different journals, but most of these journals do not help scholars collate and analyze their results or assist in promoting them to a relevant industry. However, the ultimate aim and prospect of Inventions is to help authors not only to publish their papers in the journal, but also to promote their research results to industry and assist them in realizing the purpose of technology transfer. In the future, Inventions will help authors to evaluate their technology license fees based on the valuation theory and approaches of The International Association of Consultants, Valuators and Analysts (IACVA) [1,2] and also help authors to show their patents and technologies on a network transaction platform.

The journal Inventions focuses mainly on areas that include:

- $\quad$ Patent-based/extended/reviewed inventions in engineering;

- Innovation/inventions in systems;

- Innovation/inventions in devices;

- Innovation/inventions in methods;

- Innovation/inventions in composition;

- Innovation/inventions in processes;

- Innovation/inventions in products;

- Innovation/inventions in design;

- Innovation/inventions in advanced technologies.

Our idea regarding the first item on the list is mainly to allow research scholars to concentrate their research resources on innovative and inventive research, with the aim of creating more industrial value now and for the future and to improve the environment and living conditions. This theme-patent-based/extended inventions-supports such an idea. Papers concerned with patent-reviewed inventions are particularly important. Currently, the online patent query database has tended to be complete, but the format of patent writing in many countries does not fit the reading 
habits of many readers. Inventions hopes to invite professional scholars to collate, and rewrite if necessary, patent-reviewed inventions papers to make them more universally acceptable.

However, Inventions is a new journal and is loaded with our expectations and vision, and the realization of this plan and prospects will need the collaboration and support of many experts and scholars.

\section{References}

1. The International Association of Consultants, Valuators and Analysts (IACVA). Available online: http://www.iacva.org/index.php (accessed on 30 June 2014).

2. Qcount: Intangible Asset Valuation System (Chinese Version). Available online: https://www. ipqcount.com/ (accessed on 27 June 2014).

(c) 2015 by the authors; licensee MDPI, Basel, Switzerland. This article is an open access article distributed under the terms and conditions of the Creative Commons by Attribution (CC-BY) license (http://creativecommons.org/licenses/by/4.0/). 